\title{
LETRAMENTOS EM DISPUTA: O EMBATE ENTRE TRADIÇÃO E PRÁTICAS LITERÁRIAS DE REEXISTÊNCIA NO EXAME NACIONAL DO ENSINO MÉDIO
}

\author{
LITERACIES IN DISPUTE: THE CLASH BETWEEN TRADITION AND LITERARY \\ PRACTICES OF RE-EXISTENCE IN THE BRAZILIAN NATIONAL HIGH SCHOOL EXAM
}

\author{
Marcel Alvaro de Amorim**** \\ Tiago Cavalcante da Silva***
}

\begin{abstract}
RESUMO
Uma breve leitura das provas do Exame Nacional do Ensino Médio (Enem) dos últimos anos revela-nos que, em fricção com discursos da tradição literária brasileira, servem de objeto de análise das questões da área de Linguagens, Códigos e suas Tecnologias textos literários que se assentam em práticas discursivas de reexistência. Nesse sentido, à luz da Linguística Aplicada Indisciplinar, das teorias dos Letramentos e da abordagem teórico-metodológica da Análise Dialógica do Discurso, este artigo visou a investigar quais letramentos literários são (des)legitimados nas questões do Enem construídas a partir de textos literários que se constituem estética e discursivamente como discursos de reexistência. Para tanto, tomamos como base para a construção de nosso corpus as provas do Enem aplicadas nos anos de 2018, 2019 e 2020. Como conclusão, é possível afirmar que, apesar da relativa presença de textos literários de reexistência nessas provas, percebem-se ainda fricções entre abordagens de letramentos mais tradicionais e aquelas abertamente ideológicas.
\end{abstract}

Palavras-chave: Enem; letramentos; letramentos literários; letramentos de reexistência.

\section{ABSTRACT}

A brief reading of the Brazilian National High School Examination (Enem) exams in recent years reveals that, in friction with discourses from the Brazilian literary tradition, literary texts that are based on discursive practices of re-existence coexist as objects of analysis within the area of Languages, Codes and its Technologies. In this sense, in the light of Indisciplinary Applied Linguistics, Literacy theories and the theoretical-methodological approach of Dialogical Discourse Analysis, this paper aims at investigating which literary literacies are (dis)legitimized in the Enem questions constructed based on literary texts that are aesthetically and discursively constituted as discourses of re-existence. In order to do so, exams from 2018 to 2020 of Enem were analyzed. In conclusion, it is possible to state that, despite the relative presence of re-existence literary texts in these exams, frictions between more traditional literacy approaches and those openly ideological are still perceived.

Keywords: Enem; literacies; literary literacies; re-existence literacies.

\section{APRESENTAÇÃO}

\author{
"Olhei no espelho, Ícaro me encarou \\ Cuidado, não voa tão perto do Sol \\ Eles num guenta te ver livre, imagina te ver rei \\ $\mathrm{O}$ abutre quer te ver drogado pra dizer: $\mathrm{O}$, num falei?! \\ No fim das conta é tudo Ismália, Ismália \\ Ismália, Ismália \\ Ismália, Ismália \\ Quis tocar o céu, mas terminou no chão \\ Ter pele escura é ser Ismália, Ismália \\ Ismália, Ismália \\ Ismália, Ismália \\ Quis tocar o céu, mas terminou no chão \\ (Terminou no chão)"1
}

Estamos em travessia, e o discurso literário, com sua potência ética e estética, é também arena de disputas e movências. Entre o céu e o mar de Ícaro e Ismália, há, como na letra de Emicida, outros atravessamentos constituintes, fundados por vozes em embate: "Eles num guenta te ver livre, imagina te ver rei". Fundem-se, aqui, textos canônicos, consagrados na história da literatura ocidental, como o mito grego "Ícaro" e o poema brasileiro "Ismália", de Alphonsus

\footnotetext{
* Instituto Federal do Rio de Janeiro (IFRJ), São João de Meriti, RJ, Brasil.

** Universidade Federal do Rio de Janeiro (UFRJ), Rio de Janeiro, RJ, Brasil. marceldeamorim@yahoo.com.br Orcid: https://orcid.org/0000-0002-8840-8371

***Colégio Pedro II (CPII), Rio de Janeiro, RJ, Brasil. tcavalcantes@gmail.com

Orcid: https://orcid.org/0000-0003-3121-7715

1. Emicida - Ismália part. Larissa Luz \& Fernanda Montenegro.
} 
de Guimaraens, com um outro discurso, daqueles que, de "pele alvo", estão postos à margem do direito ao voo. Se a literatura expõe, mais abertamente hoje, essa fratura-fricção entre discursos canônicos e aqueles que buscam reexistir a essas vozes, como tal movimento chega ao contexto educacional? E mais: como os exames oficiais avaliativos, como o Exame Nacional do Ensino Médio (Enem), mobilizam essa frequência discursiva?

No presente artigo, temos por objetivo - dada a sua importância como principal instrumento de avaliação da educação básica e de acesso ao ensino superior no Brasil - investigar de que modo aparecem/são operacionalizados os letramentos literários na prova de Linguagens, Códigos e suas Tecnologias do Enem aplicadas entre 2018 e 2020, entendendo especialmente que letramentos literários são (des)legitimados nesse exame a partir da análise de questões que dialoguem com práticas literárias de reexistência (SOUZA, 2011; NEVES, 2017; AMORIM \& SILVA, 2019) ressignificadoras de discursos sobre raça, gênero e sexualidade. Tal compreensão permitirá criar inteligibilidade sobre a forma como as diferentes vozes discursivas que disputam o campo literário brasileiro se movimentam e são abordadas entre as/nas 45 questões objetivas que compõem cada edição da prova.

O Enem foi criado em 1998 com o objetivo de avaliar a educação básica no Brasil2 ${ }^{2}$ A partir de 2005, com a criação do ProUni (Universidade para Todos), o exame passou a ser aceito para a concessão de bolsas em universidades particulares. Contudo, foi apenas em 2009 que o Enem começou a substituir os principais vestibulares do país, compondo-se, então, de uma proposta de produção textual e 180 questões objetivas, distribuídas nas quatro áreas do conhecimento indicadas inicialmente pelos Parâmetros Curriculares Nacionais do Ensino Médio em 2000, a saber: Linguagens, Códigos e suas Tecnologias, Matemática e suas Tecnologias, Ciências Humanas e suas Tecnologias e Ciências da Natureza e suas Tecnologias. Tal modelo se tornou um critério para participação no programa de Financiamento Estudantil (FIES), sendo igualmente aceito por todas as universidades e institutos públicos federais por meio do Sistema de Seleção Unificada ( $\mathrm{SiSu}$ ), que permitiu que estudantes de diferentes áreas do Brasil, por meio de um mesmo exame, pudessem concorrer a vagas nos cursos de graduação das mais diversas instituições públicas de ensino superior do país.

No que concerne à área de Linguagens, Códigos e suas Tecnologias, nosso objeto de estudo aqui, as 45 questões objetivas são construídas a partir de uma Matriz de Referência de Competências, Habilidades e Objetos de Conhecimento que movimentam saberes de Línguas Estrangeiras (Inglês e Espanhol, conforme a escolha do estudante), Língua Portuguesa e Literatura (com ênfase quase total na Literatura Brasileira), Educação Musical, Educação Física e Informática. Cada uma dessas 45 questões é constituída, de modo geral, a partir de um pequeno texto, de gêneros, esferas discursivas e temáticas variadas. Entre eles, aparecem textos literários diversos, como poemas, letras de música, contos, crônicas, romances, especialmente de autoria canônica, tais como Machado de Assis, Manuel Bandeira, Graciliano Ramos, Monteiro Lobato, Clarice Lispector, dentre outros. Junto a essas autorias, começou-se a ensaiar, na última década, um trabalho com textos menos próximos ao centro do campo literário (BOURDIEU, 1996).

Nesse sentido, como já apontamos, interessa-nos especialmente analisar que visões de letramentos literários são (des)legitimadas na abordagem de textos dessas autorias às margens do campo literário - denominadas por documentos como a Base Nacional Comum Curricular (BNCC) de periférico-marginais, mas aqui intituladas literaturas de reexistência (AMORIM \& SILVA, 2019; SILVA, 2020) -, especificamente nos exames de 2018 a 2020, quando se nota, na política brasileira, um alavancamento de uma agenda ideológica conservadora ${ }^{3}$. Na tentativa de criar inteligibilidades sobre essa questão, partimos de um arcabouço teórico-metodológico que coloca em diálogo, numa perspectiva Indisciplinar da Linguística Aplicada, os estudos da literatura sob vieses culturais, teorias dos letramentos e a Análise Dialógica do Discurso (ADD).

Para tanto, apresentamos, na próxima seção, uma discussão sobre a literatura na prova do Enem e sobre o embate discursivo entre diferentes práticas literárias nas questões desse exame. Na segunda seção deste artigo, realizamos uma leitura dos principais discursos sobre letramentos e letramentos literários que têm sido ventilados nas esferas educacionais/acadêmicas, para, na quarta e quinta seções, respectivamente, descrevermos a metodologia de pesquisa elencada e apresentarmos a análise das questões do Enem selecionadas. Por fim, nas considerações finais,

2. É importante ressaltar que, para além de avaliar a educação básica, entendemos, em diálogo com Scaramucci (2004), que avaliações em larga escala como o Enem também terminam por se constituir como formas de controle ao currículo escolar e ao próprio trabalho docente.

3. Para mais informações sobre a recente emergência de uma agenda política conservadora, construída sobre discursos de extrema direita, no Brasil, sugerimos a leitura do capítulo "A reemergência da direita brasileira", de Luiz Felipe Miguel, em GALLEGO, E. S. O ódio como política: a reinvenção das direitas no Brasil. São Paulo: Boitempo, 2018. 
tecemos algumas reflexões e encaminhamentos possíveis a partir dos resultados - sempre em movência - desta pesquisa.

\section{A CONFIGURAÇÃO NO ENEM E O EMBATE DISCURSIVO ENTRE DIFERENTES PRÁTICAS LITERÁRIAS}

A prova de Linguagens, Códigos e suas Tecnologias do Enem se constitui a partir de uma Matriz de Referência organizada em a) Eixos Cognitivos (comuns a todas as áreas do conhecimento), b) Competências, c) Habilidades e d) Objetos de Conhecimento. São cinco os Eixos Cognitivos elencados: I. Dominar linguagens (DL); II. Compreender fenômenos (CF); III. Enfrentar situações-problema (SP); IV. Construir argumentação (CA); e V. Elaborar propostas (EP). Pelo detalhamento desses eixos, como se lê na íntegra da Matriz referida, depreende-se que, em tese, as questões de leitura da área de Linguagens, especificamente, buscam: verificar o domínio da norma culta da língua; aferir a compreensão dos textos (incluindo-se, aqui, os textos da esfera literária) dentro de um determinado contexto material, em seus processos histórico-geográficos, a fim de enfrentar situações-problema; observar se o candidato sabe selecionar, organizar e relacionar informações e conhecimentos, com o objetivo de enfrentar situações-problema e produzir interpretações possíveis.

No tocante às Competências e Habilidades, a lista se distribui em nove Competências, relacionadas a trinta diferentes Habilidades. Dentre elas, destacam-se as que se relacionam, em nossa compreensão, à abordagem da leitura literária em específico, o recorte que nos interessa neste artigo:

Competência de área 4 - Compreender a arte como saber cultural e estético gerador de significação e integrador da organização do mundo e da própria identidade.

H12 - Reconhecer diferentes funções da arte, do trabalho da produção dos artistas em seus meios culturais.

H13 - Analisar as diversas produções artísticas como meio de explicar diferentes culturas, padrões de beleza e preconceitos.

H14 - Reconhecer o valor da diversidade artística e das inter-relações de elementos que se apresentam nas manifestações de vários grupos sociais e étnicos.

Competência de área 5 - Analisar, interpretar e aplicar recursos expressivos das linguagens, relacionando textos com seus contextos, mediante a natureza, função, organização, estrutura das manifestações, de acordo com as condições de produção e recepção.

H15 - Estabelecer relações entre o texto literário e o momento de sua produção, situando aspectos do contexto histórico, social e político.

H16 - Relacionar informações sobre concepções artísticas e procedimentos de construção do texto literário.

H17 - Reconhecer a presença de valores sociais e humanos atualizáveis e permanentes no patrimônio literário nacional.

Competência de área 6 - Compreender e usar os sistemas simbólicos das diferentes linguagens como meios de organização cognitiva da realidade pela constituição de significados, expressão, comunicação e informação.

H1 8 - Identificar os elementos que concorrem para a progressão temática e para a organização e estruturação de textos de diferentes gêneros e tipos.

H19 - Analisar a função da linguagem predominante nos textos em situações específicas de interlocução.

H20 - Reconhecer a importância do patrimônio linguístico para a preservação da memória e da identidade nacional (BRASIL, 2015, p. 2-3).

Como se pode observar pela Competência 4, a prova do Enem deveria considerar a elaboração das questões relativas a textos literários a partir da chave da diversidade. A literatura apareceria, desse modo, como um "saber cultural e estético" produzido por "vários grupos sociais e étnicos" em seus diversos meios. A tal competência soma-se a Competência 5, em que o termo "texto literário" aparece de modo mais objetivo: as produções literárias são concebidas, nesse sentido - tanto em seu processo de construção quanto em sua recepção -, dentro de sua materialidade histórica, social e política. Na Habilidade 17 (H17), destaca-se a ideia dessa mesma produção literária como algo da ordem de um "patrimônio nacional"; no entanto, não fica evidente que concepção de patrimônio está posta aqui - se aquela relacionada ao cânone literário, ou se outra, relativa à ideia de uma produção literária complexa, que representaria a diversidade cultural brasileira destacada na Competência 4.

Por fim, de caráter mais genérico, a Competência 6 parece também contemplar, em nossa visão, a abordagem do texto literário, uma vez que se refere a "sistemas simbólicos das diferentes linguagens", apontando para a necessidade de se observar a progressão/estruturação dos diferentes gêneros e as variadas funções assumidas pela linguagem em "situações específicas de interlocução". O termo "patrimônio" surge novamente, na Habilidade 20 (H20), relacionando-se a língua à "preservação da memória e da identidade nacional" e nos suscitando, mais uma vez, a dúvida: estaria, nas habilidades do Enem, o sistema simbólico da linguagem literária concebido a partir da ótica de um patrimônio cultural diverso? E a ideia de língua culta, que ganha destaque no Eixo Cognitivo I? Essa seria a 
variante linguística que serviria de alicerce a uma concepção do texto literário como um "patrimônio" de uma cultura marcada pela diversidade étnica e social? O documento nos lança, assim, a um lugar de incertezas.

Os Objetos de Conhecimento associados à Matriz de Referência não nos ajudam muito a encontrar respostas a essas dúvidas:

- Estudo do texto literário: relações entre produção literária e processo social, concepções artísticas, procedimentos de construção e recepção de textos - produção literária e processo social; processos de formação literária e de formação nacional; produção de textos literários, sua recepção e a constituição do patrimônio literário nacional; relações entre a dialética cosmopolitismo/localismo e a produção literária nacional; elementos de continuidade e ruptura entre os diversos momentos da literatura brasileira; associações entre concepções artísticas e procedimentos de construção do texto literário em seus gêneros (épico/narrativo, lírico e dramático) e formas diversas; articulações entre os recursos expressivos e estruturais do texto literário e o processo social relacionado ao momento de sua produção; representação literária: natureza, função, organização e estrutura do texto literário; relações entre literatura, outras artes e outros saberes (BRASIL, 2015, p. 15-6).

Conforme se pode observar, destacam-se, de novo, algumas ideias já presentes nas Competências e Habilidades antes sublinhadas: o texto literário, em sua dimensão de produção e recepção dentro de um contexto material específico; a estruturação dos diferentes gêneros literários e seus recursos expressivos; a constituição do patrimônio literário nacional; dentre outros. Chama a atenção, porém, a referência mais direta a uma perspectiva talvez mais historiográfica do estudo das literaturas, quando se mencionam os "elementos de continuidade e ruptura entre os diversos momentos da literatura brasileira". Além disso, outro elemento de dúvida, mais uma vez, é como a Matriz definiria o chamado "patrimônio literário nacional", se por uma via nacionalista e historiográfica pura e simples, ou se pela via da complexidade e da diversidade de que se compõe a cultura brasileira.

Para começarmos a desenhar possíveis reflexões que alentem tais dúvidas, é preciso que visitemos alguns conceitos importantes, tais como campo literário (BOURDIEU, 1996) e cânone (FISCHER et al. 2012; FISCHER, 2014; REIS, 2013). Em As regras da arte (1996), Bourdieu, pensando na configuração do campo literário na França do século XIX, assenta suas reflexões na noção de campo de poder. Para o sociólogo, a sociedade ocidental capitalista seria atravessada, em sua estrutura, por relações de poder assimétricas. Assim, o campo de poder seria definido como uma espécie de arena entre aqueles agentes ou instituições que disputam posições dominantes, isto é, o centro do campo, com seus diferentes capitais: capital econômico (renda, salário, imóveis); capital cultural (saberes reconhecidos por diplomas ou títulos); capital social (relações sociais que podem ser revertidas em capital); e capital simbólico (prestígio e/ ou honra). Quanto mais domínio sobre esses capitais, mais central a posição assumida pelos agentes e instituições.

É nessa perspectiva que Bourdieu pensa também a ideia de campo literário. Pautando-se na produção literária do século XIX na França e em sua circulação, o estudioso define o campo literário como um lugar engendrado por um "princípio de hierarquização externa" (os prêmios, as condecorações, a circulação no mercado editorial, o sucesso de vendagem) e um "princípio de hierarquização interna" (consagração específica entre os pares, não concessão às demandas do grande público). No que toca à produção literária brasileira, pensamos esses princípios alinhados à disputa entre projetos estéticos que se hospedam às margens do centro de poder, fazendo da literatura um lugar de resistência e reelaboração estética da opressão e da violência (AMORIM \& SILVA, 2019; SILVA, 2020), e aqueles projetos que atendem à expectativa do mercado editorial, da crítica, da academia e são construídos por vozes socialmente legitimadas em sua raça, gênero, classe e orientação sexual.

É assim que chegamos, neste ponto, ao conceito de cânone. Definimos cânone, na perspectiva da produção literária, não como uma lista de autorias e obras consagradas apenas, mas sim como uma espécie de máquina que se assenta na materialidade histórica, social, cultural, ideológica, política e que se movimenta por meio das engrenagens do mercado editorial, da crítica, da academia, da escola, dos prêmios, isto é, de fatores que legitimam literária e socialmente determinadas vozes e não outras. Reis (2013) postula, nesse sentido, a literatura como uma "instituição", isto é, como uma estrutura arquitetada socialmente e sustentada pelos referidos fatores de legitimação. Portanto, o cânone literário - posicionando-se no centro do campo de poder - funcionaria, como advoga Silva (2020), como um aparelho de "litericídio", isto é, como um aparelho que, ao fazer falar determinadas vozes, acaba por silenciar e fazer não viver tantas outras - estas marcadas por categorias muito nítidas: classe, raça, gênero, orientação sexual, dentre outros.

Se pensarmos na escola - e, também, nas próprias avaliações externas que verificam o rendimento dos estudantes da educação básica, como o Enem, foco deste artigo - como um fator de legitimação da produção literária, é possível perceber que, até pelo menos o início da década de 2010, autorias negras, indígenas, femininas, faveladas, LGBTQIA + figuravam em materiais didáticos de forma ainda mais insignificante do que hoje. Em geral, o que se 
observava era quase que unicamente a reprodução de uma historiografia literária (SCHMIDT, 2017) por si mesma por vezes um conjunto de características, datas, nomes, obras -, com vozes ilustrativas de homens brancos e filhos da classe média ou das elites econômicas do país. As autorias femininas, por exemplo, tão proeminentes, sobretudo no século XIX, pouco apareciam, começando a ter algum destaque apenas a partir do Modernismo, com Rachel de Queiroz, Cecília Meireles, Clarice Lispector, dentre outras. As vozes indígenas, africanas, faveladas e aquelas que configuram esteticamente as questões LGBTQIA + até pelo menos o que, em geral, se intitulava, nos livros didáticos, como "tendências da literatura contemporânea" (isto é, a literatura produzida nas décadas finais do século XX), eram - e, muitas vezes, ainda são - frequentemente apagadas.

Tal desenho só começa a ganhar novos contornos, como apontamos, na década de 2010, no Brasil, alguns anos depois da promulgação das leis 10.639/2003 e 11.645/2008, que, apesar de ainda não terem provocado uma inclusão significativa das temáticas que abordam no sistema educacional e nas avaliações externas nacionais, sobretudo por não terem sido completamente apropriadas por essas instâncias, tornaram obrigatórios, respectivamente, o ensino de história, cultura e literaturas africanas e afro-brasileiras e, depois, o ensino de história, cultura e literaturas indígenas. É a partir desse momento, conquista de anos de luta por parte dos movimentos negros e indígenas, que avaliações externas começam a se reconfigurar, a fim de atender à obrigatoriedade das referidas leis. Aos poucos, essas autorias começam também a fazer parte - ainda que timidamente - das provas do Enem. Neste artigo, nos interessa especialmente compreender como essas autorias são abordadas nessa prova, já que se trata de um exame nacional e que, em tese, teria de dar conta da literatura como um "patrimônio".

Fischer et. al. (2012) e Fischer (2014), tanto preocupados com as questões do ENEM construídas com base em textos literários em diversas áreas quanto com a problemática do cânone do ensino de literaturas, postulam que devemos pensar na noção de "cânones", no plural, com um surgimento muito determinado pela materialidade histórica, social, cultural, política. Assim, para os autores, é possível, por exemplo, pensar num cânone "jesuítico", do período colonial; em um cânone "pós-independência", a serviço da construção de uma identidade nacional na metade do século XIX; em um cânone de "paradigma crítico e historiográfico", com a ruptura com o nacionalismo e a reivindicação de liberdade temática, em fins do mesmo século XIX; dentre outros. É a partir dos anos 1970, porém, segundo esses autores, que o cânone acaba por se configurar como um "subproduto impensado" do vestibular, já que o acesso ao hoje ensino médio se amplia no Brasil e o número de candidatos aos exames aumenta, surgindo o vestibular unificado. Esse seria o cânone com o qual a escola, muito em função dos vestibulares, passaria a trabalhar nas décadas seguintes: um cânone historiográfico, construído por vozes nacionalistas (românticas e aquelas anteriores, com produção de caráter localista), republicanas (realistas, naturalistas e parnasianas) e modernas ("pré-modernas" e as demais).

A partir daí, os exames vestibulares fragmentam-se, mas mantêm, quase sempre, a perspectiva historiográfica, com concursos que exigem, inclusive, a leitura de autorias e obras específicas, a maior parte dessas consagradas pelos fatores de legitimação do cânone já aqui apontados. Em 2009/10, com a transformação do ENEM em um vestibular unificado, novos caminhos começam a ser apontados: substitui-se a perspectiva historiográfica por si mesma pela leitura de diferentes gêneros, sobretudo do período romântico, do Modernismo e da produção literária contemporânea. Isto levou muitos estudiosos e docentes, defensores da importância do cânone historiográfico, a afirmar que a literatura havia sido abolida do vestibular e definir a abordagem do texto literário no exame como "iliterária" ou "antiliterária" (FISCHER, 2014), já que pautada, segundo essa visão, na aferição genérica de raciocínios e habilidades de leitura.

Retomamos, assim, nossa indagação inicial: que letramentos literários estão, hoje, sendo (des)legitimados pela prova de Linguagens, Códigos e suas Tecnologias na abordagem de autorias que se colocam em fricção, em disputa, especialmente no período posterior ao analisado por Fischer (2014)? Para refletir sobre essa questão, buscaremos, na seção seguinte, dialogar com alguns conceitos de letramentos e letramentos literários que têm sido ventilados nas esferas educacionais e acadêmicas.

\section{DOS LETRAMENTOS AOS LETRAMENTOS LITERÁRIOS DE REEXISTÊNCIA}

Como nosso interesse se centra na compreensão sobre o modo como os letramentos literários foram operacionalizados nas edições do Enem entre 2018 e 2020 a partir da leitura de questões que abordam textos do que 
chamamos de literaturas de reexistência (AMORIM \& SILVA, 2019; SILVA, 2020), nesta seção, traçaremos um breve percurso das principais teorias de letramentos que podem, em alguma instância, dialogar com as questões que nos propomos a analisar. Desse modo, é nossa intenção construir um quadro dos estudos dos letramentos - à semelhança do que realizou Soares (1998) -, de modo a possibilitar que esses conceitos sejam convocados, quando necessário, em nossa leitura do corpus.

O conceito de letramento foi efetivamente ventilado por discursos acadêmicos internacionais da área de educação na década de 1980, especialmente após a publicação da obra Literacy in theory and practice (1984), do pesquisador britânico Brian Street. No Brasil, apesar de uma certa concepção de letramentos se encontrar discursivizada por Paulo Freire em seu A importância do ato de ler (2017), sobretudo quando o autor discute a relação da leitura da palavra com a leitura do mundo no capítulo "A importância do ato de ler", escrito originalmente em 1981, apenas na segunda metade da década de 1980 as discussões sobre o letramento aparecem sob esse rótulo.

Inicialmente, o termo "letramento" é convocado, em nosso país, pelos escritos de Mary Kato, em No mundo da escrita (1986), e de Leda Tfouni, em Adultos não alfabetizados (1988). No entanto, neste artigo, dialogaremos especialmente com as apropriações do conceito de letramentos realizadas por Kleiman (1995), Street (2003) e Soares (1998; 2002), por esses autores apresentarem concepções que continuam a ser refratadas em discursos educacionais ainda em circulação. Em relação aos letramentos literários, procuraremos discuti-los em diálogo com Paulino (2001), Soares (2008), Paulino e Cosson (2009) e Amorim et al. (no prelo). Por fim, partindo do diálogo com Souza (2011), Neves (2017), Amorim \& Silva (2019) e Silva (2020), pensamos os letramentos literários como práticas de reexistência.

Kleiman (1995) compreende o conceito de letramento como relacionado às práticas de leitura e escrita e ao impacto dessas práticas na sociedade. De acordo com a autora, os letramentos seriam "um conjunto de práticas sociais que usam a escrita como sistema simbólico e como tecnologia em contextos específicos, para objetivos específicos..." (KLEIMAN, 1995, p. 18-19), sendo o letramento desenvolvido na escola apenas um tipo de prática de letramento, e não o único. Nesse sentido, Kleiman traz para os estudos dos letramentos a noção de agências de letramento, que se constituiriam por/em diferentes espaços, tais como a rua, a igreja, a família, o trabalho, além da própria escola. Esses espaços, apesar de apresentarem orientações diferentes, são, para a autora, igualmente importantes para os processos de letramentos.

Ademais, no movimento de caracterização da escola como a mais importante dentre as agências de letramento, Kleiman recorre à distinção efetuada por Street entre letramento autônomo e letramento ideológicot. A partir dessa distinção, a abordagem autônoma dos letramentos se relacionaria à tarefa de

introduzir letramento a pessoas, vilas, juventudes urbanas pobres e 'não letradas' etc. [Isso teria] um efeito na melhoria das capacidades cognitivas dessas pessoas, melhorando suas possibilidades econômicas, tornando-as melhores cidadãos, independentemente das condições sociais e econômicas que contribuem para o seu "não letramento" (STREET, 2003, p. 77).

Essa visão parece considerar o letramento como uma variável aparentemente desvinculada do contexto social e que, muitas vezes, é equiparada à ideia de progresso, sendo propiciadora de benefícios evidentes para indivíduos ou nações: saber ler e escrever a partir do uso da chamada norma padrão, por exemplo, garantiria ao cidadão um lugar na sociedade, sua ascensão social e, por conseguinte, o desenvolvimento dessa própria sociedade.

O modelo ideológico de letramento, por sua vez, buscando compreender "a natureza social do letramento [e as] implicações políticas e ideológicas das instituições" (STREET, 2014, p. 111) onde ele é usado, se configura como uma "[...] visão culturalmente mais sensível de práticas de letramento que variam de contexto para contexto [...]" (STREET, 2003, p. 77). Dessa forma, o letramento é visto como uma prática social e não como uma simples habilidade técnica ou neutra, sendo sempre atravessado por princípios epistemológicos que são construídos em sociedade.

Soares também dialoga com os postulados de Street, especialmente com a visão ideológica dos letramentos, ao entender como cidadãos letrados aqueles

Indivíduos ou grupos sociais que dominam o uso da leitura e da escrita e, portanto, têm habilidades e atitudes necessárias para uma participação viva e competente em situações em que práticas de leitura e/ou escrita têm uma função essencial, mantêm com os outros

4. Apontamos que a divisão entre os letramentos autônomos e os ideológicos tem caráter apenas didático. Compreendemos todos os letramentos como ideológicos; no entanto, o que Street chama de letramento autônomo parece estar relacionado a um enquadre ideológico que privilegia a técnica sobre a criticidade, a reprodução sobre transformação e o universal sobre o diverso, isto é, a discursos tradicionais sobre aqueles mais progressistas. 
e com o mundo que os cerca formas de interação, atitudes, competências discursivas e cognitivas que lhes conferem um determinado e diferenciado estado ou condição em uma sociedade letrada (SOARES, 2002, p. 146).

O letramento seria, dessa forma, para a autora, um efeito do processo das ações de ensinar e aprender a ler e escrever, "o estado ou condição que adquire um grupo social ou um indivíduo como consequência de ter se apropriado da escrita" (SOARES, 1998, p. 18). Dessa forma, Soares se foca nas consequências linguísticas, sociais, culturais e políticas do letramento para a formação de cidadãos.

No campo do ensino de literaturas, a ideia de letramentos foi apropriada, inicialmente, por Graça Paulino entre as décadas de 1990 e 2000. Em texto de 2001 no qual sistematiza o conceito, a autora compreende o letramento literário como a inserção do sujeito no universo da leitura e da escrita do texto literário, entendido como aquele que se relaciona "ao trabalho estético da língua, à proposta de pacto ficcional e à recepção não-pragmática" (PAULINO, 2001, p. 117). Nesse sentido, um cidadão que fosse literariamente letrado seria aquele que "cultivasse e assumisse como parte de sua vida a leitura desses textos, preservando seu caráter estético, aceitando o pacto proposto e resgatando objetivos culturais em sentido mais amplo, e não objetivos funcionais ou imediatos para seu ato de ler" (PAULINO, 2001, p. 117-118). Assim, Paulino parece construir sua definição sob uma visão de literatura que coloca, em primeiro lugar, o trabalho estético e o plano da língua, assim como uma função "não pragmática" do literário. A preservação desse caráter estético imanente e o resgate de objetivos culturais na leitura do literário seriam, então, ações necessárias à efetivação do letramento literário.

Soares, por sua vez, em Leitura e Democracia Cultural (2008), recorre aos estudos de Street na tentativa de repensar a leitura literária - não se apropriando diretamente do termo letramentos - a partir das perspectivas autônoma e ideológica propostas pelo autor. Como leitura literária autônoma, Soares compreende a leitura da literatura que seria vista como contendo um valor em si, sendo enxergada como naturalmente boa, legítima e causadora de efeitos positivos sobre o indivíduo. A leitura literária ideológica, por sua vez, é, para a autora, uma visão de leitura que se assume como uma prática ideológica, "enraizada em e difusora de visões de mundo, veículos de inculcação de valores, podendo, portanto, ter efeitos e consequências os mais diversos" (SOARES, 2008, p. 30).

Cosson é, no entanto, o autor que popularizou o termo "letramento literário", não apenas por meio do livro Letramento Literário (2006) - que, apesar de não sistematicamente definir o conceito, apresenta orientações e métodos para a efetivação dos letramentos literários na escola -, mas também a partir da construção de uma definição mais acurada desse conceito junto à Paulino, que, então, revisa sua definição anterior. Nessa nova definição, Paulino e Cosson (2009, p. 67) entendem por letramento literário "o processo de apropriação da literatura enquanto construção literária de sentidos".

Primeiramente, compreende-se por processo o letramento que se faz numa progressão contínua e mutável, não se restringindo aos moldes da escola. Em segundo lugar, fala-se de apropriação da literatura. Nesse contexto, a literatura é uma espécie de objeto que pode e deve ser apropriado como literatura por alguém. Sendo assim, existe a necessidade de aproximação entre objeto - a literatura - e sujeito que o manuseia - o leitor. Além disso, nessa visão, o próprio termo literatura é ampliado para expressar as muitas possibilidades literárias que cerceiam o mundo cultural. Por fim, por "construção literária de sentidos" Cosson e Paulino entendem um processo que advém 1) de uma interação verbal mais intensificada, uma vez que ler literatura, para os autores, é um ato de imersão por meio de palavras e 2) "[d] o reconhecimento do outro e [d]o movimento de desconstrução/construção do mundo que se faz pela experiência da literatura" (COSSON e PAULINO, 2009, p. 69).

Atualmente, diversos pesquisadores procuram ampliar o conceito de letramentos literários, ressignificando-o. Em Amorim et al. (no prelo), procuramos realizar esse movimento de ressignificação a partir de um diálogo mais explícito com a visão ideológica de letramentos proposta por Street (2003) e concepções da filosofia da linguagem do Círculo de Bakhtin. Compreendemos, então, letramentos literários como

[...] movimentos contínuos, responsivos e ideológicos de apropriação do literário como construção de sentidos sobre os textos, sobre nós mesmos e sobre a sociedade, o que envolve: 1) a compreensão do texto literário como um tecido em construção ou texto infinito, com significados sempre em debate, abertos a questionamentos e contestações; 2) a possibilidade de construção contínua de atitudes responsivas - sempre ideologicamente guiadas - na integração com textos literários em diferentes contextos; e 3) um movimento exotópico de encontro com o outro e consigo, de alteridade, pelo estético, numa perspectiva humanizante do ser humano coisificado (AMORIM et al, no prelo, n.p.).

Ademais, ao pensar os letramentos literários em diálogo com a ideia de letramento ideológico, procuramos pensar não apenas no comportamento observado no encontro com o texto literário em si, mas também em quais 
conceitos, ideologias e significados são refratados pelos leitores nesse encontro a partir de suas vivências, o que pode possibilitar a efetivação de um movimento exotópico de encontro com o outro por meio do literário. Entendemos, com efeito, a exotopia, a partir de Bakhtin $(2011$; 2017), como o movimento pelo qual a pessoa sai do seu lugar para vivenciar o lugar do outro, mas leva consigo o que a constitui. Desse modo, o leitor completa o outro a partir de si e possui um excedente de visão que é só seu, formado pela integração dos elementos de si e do outro (AMORIM, NASCIMENTO e SANTOS, 2021).

Dialogando mais diretamente com a temática proposta para este artigo, Neves (2017) correlaciona os letramentos literários a práticas de reexistência ao pensar o Slam como letramento de reexistência. A autora considera os Slams a partir desse prisma ao reconhecê-los como poesia que (sobre)vive (às)nas ruas, circulando em estações, ocupando espaços públicos e invadindo instituições educacionais por meio de iniciativas diversas. As batalhas de Slam, de acordo com a autora, garantem "o empoderamento das classes minoritárias e estigmatizadas, dão voz aos emudecidos pelo sistema, valorizam a arte popular, marginal, periférica, funcionam como resistência políticoideológica fortalecendo seu éthos - são, portanto, letramentos de reexistência, no neologismo de Ana Lúcia S. Souza (2011), quando a autora se refere aos raps" (NEVES, 2017, p. 106, grifos da autora).

Em Amorim \& Silva (2019) e Silva (2020), também em diálogo com Souza (2011), propusemos uma ampliação do conceito de letramento literário de reexistência na tentativa de criar inteligibilidades sobre outros modos de construir o literário que não os canônicos; aqueles performados por "autoras e autores periféricos, que ressignificam esteticamente a opressão de que são vítimas, fazendo da literatura um terreno de sobrevivência ao colonialismo, ao racismo, a toda e qualquer forma de depreciação das subjetividades não hegemônicas" (SILVA, 2020, p. 276). Com efeito, compreendemos os letramentos literários de reexistência como o trabalho, por meio da leitura/escrita literária, com

uma prática artística de linguagem que permite aos sujeitos historicamente violentados e discriminados - como negros/as, pobres homossexuais, indígenas, mulheres - a possibilidade de agência e ressignificação estético-políticas de suas identidades (AMORIM \& SILVA, 2019, p. 173).

Por fim, tendo dialogado com diferentes concepções de letramentos, letramentos literários e de reexistência, passaremos, na próxima seção, à apresentação do percurso metodológico da pesquisa realizada.

\section{PERCURSO METODOLÓGICO}

A análise apresentada na próxima seção ocupa-se de questões das edições do Enem entre 2018 e 2020 - que abordam textos das chamadas literaturas de reexistência, especialmente aqueles atravessados por discussões sobre raça, gênero e sexualidade. É nossa intenção maior compreender que discursos sobre os letramentos literários são (des)legitimados nessas avaliações. Sendo assim, este artigo, construído sob uma visão Indisciplinar da Linguística Aplicada (MOITA LOPES, 2006) - que tem se constituído como uma importante área de investigação da relação entre literaturas e ensino (AMORIM \& SILVA, 2020) -, dialoga com a Análise Dialógica do Discurso (ADD) na tentativa de criar inteligibilidades sobre o corpus selecionado.

Segundo Brait (2004), a ADD tem por objetivo a compreensão dos processos de construção de sentidos e seus efeitos no mundo social. Para isso, parte da ideia de que os significados são construídos na interação social, ou seja, no diálogo entre sujeitos compreendidos como discursivos, históricos e culturais. Com efeito, na busca pela compreensão dos textos/discursos sob análise, a ADD procura apontar os modos de construção de sentidos a partir da análise de materialidades semióticas em diálogo com o contexto sócio-histórico mais amplo. Nesse sentido, uma análise dialógica do discurso se preocuparia com as

1) formas e tipos de interação discursiva em sua relação com as condições concretas; 2) formas dos enunciados ou discursos verbais singulares em relação estreita com a interação da qual são parte, isto é, os gêneros dos discursos verbais determinados pela interação discursiva na vida e na criação ideológico; 3) partindo disso, revisão das formas da língua em sua concepção linguística habitual (VOLÓCHINOV, 2017, p. 220).

Ressaltamos que consideraremos, no movimento de análise, que todo enunciado dialoga com outros enunciados já ditos antes dele, antecipando, inclusive, possíveis atitudes responsivas por parte de enunciados posteriores (BAKHTIN, 2016; VOLÓCHINOV, 2017). Dessa forma, a interação é compreendida para além da situação 
imediata, referindo-se a todas aquelas em que pessoas se dirijam umas às outras, mesmo à distância (SOBRAL e GIACOMELLI, 2016). Ademais, é importante, no movimento da análise dialógica, o entendimento dos signos como ideológicos, sendo o discurso sempre construído a partir de uma certa posição social e histórica de um enunciador diante de seu interlocutor (VOLÓCHINOV, 2017). Nesse sentido, compreendemos que "nenhum dizer é inocente, ingênuo, gratuito, pois sempre está ligado aos interesses de quem diz (mesmo que a pessoa nem saiba que interesses são esses)" (SOBRAL e GIACOMELLI, 2016, p. 1083).

Por fim, apontamos também que consideramos a linguagem como de natureza heterodiscursiva. De acordo com Bakhtin (2015, p. 113), "a palavra bifocal é sempre interiormente dialogada. A língua(gem) é, desse modo, necessariamente saturada ideologicamente a partir de diferentes opiniões, pontos de vista e horizontes conceituais, constituindo-se como uma verdadeira arena de embates discursivos. Em outros termos, no heterodiscurso, diversas "vozes sociais se entrecruzam continuamente de maneira multiforme, processo em que se vão também formando novas vozes sociais" (FARACO, 2009, p. 58).

Passemos, finalmente, à análise das questões do Enem selecionadas para este artigo.

\section{ANÁLISE DAS QUESTÕES DO ENEM}

Como já posto, selecionamos, para fins de análise, as provas de Linguagens, Códigos e suas Tecnologias do Enem aplicadas entre 2018 e 2020, momento de intensificação de uma pauta conservadora no país. Ainda que não tenha obtido êxito, no sentido de sua aprovação pelo Congresso, projetos como o Escola Sem Partido - que buscava controlar o que se pode ou não trabalhar na sala de aula da educação básica - continuam com sua base ideológica sedimentada na sociedade. Nesse sentido, quaisquer reflexões sobre raça, gênero, classe e sexualidade, por exemplo, na escola, são definidas como doutrinação ideológica. Ressaltamos que construímos esta análise a partir do exemplar azul dos exames ${ }^{5}$, apesar das questões serem encontradas em todas as versões, mas em ordens diversas.

Uma análise global da prova de 2018 nos revela dados significativos: das 45 questões referentes à área de Linguagens, Códigos e suas Tecnologias, apenas 15 buscam abordar diretamente os saberes de leitura literária em português dos estudantes. Dessas 15 questões, 11 partem de textos de autorias geralmente consideradas como consagradas no centro do campo literário brasileiro, figurando em livros didáticos, circulando no mercado e sendo reconhecidas pela crítica especializada: Guimarães Rosa, Torquato Neto, Leonardo Fróes, Ricardo Freire, Martha Medeiros, Joaquim Osório Duque Estrada, Marques Rebelo, Eduardo Galeano, Manoel de Barros, Graciliano Ramos e Ivan Ângelo. Os outros textos são assinados por Cuti, Natália Borges Polesso, Angélica Freitas e Stella do Patrocínio. Os três primeiros movimentam-se pela academia e pelo mercado, sendo Natália Borges e Angélica Freitas, autoras da reconhecida editora Companhia das Letras. Apenas Stella do Patrocínio se configura como uma voz à parte desse circuito, sendo nomeada como poeta somente depois de sua morte, quando Viviane Mosé organiza seus textos e os publica sob o título de Reino dos bichos e dos animas é o meu nome (2001), pela Azougue Editorial.

Tematicamente, apesar de autores como Leonardo Fróes, Torquato Neto, Ivan Ângelo e Marques Rebelo aparecerem, na prova, por meio de textos que ensaiam/denunciam a opressão e a desigualdade, somente Cuti, Natália Borges Polesso, Angélica Freitas e Stella do Patrocínio figuram por intermédio de textos que põem diretamente em relevo questões de raça, gênero e sexualidade, elencadas como foco deste artigo. Observa-se, assim, já na arquitetura das questões de leitura literária da prova de 2018, uma complexidade muito maior do que supúnhamos. A disputa entre os letramentos literários ali materializados não se simplifica entre vozes tradicionalmente eleitas no cânone e aquelas que seriam hospedadas às margens do campo literário por meio dos fatores de legitimação apontados por Reis (2013). É interessante observar, já de início, um recorte muito claro de gênero: entre as onze vozes que consideramos tradicionalmente legitimadas em nossa literatura, apenas Martha Medeiros figura como autoria feminina, sendo esta, inclusive, uma autora muito mais reconhecida pela circulação no mercado que pela Academia e/ou pela Crítica. Ainda entre essas onze vozes, outro dado que se revela interessante é o de que nenhum dos homens é negro. São, em sua maioria, homens brancos, de classe econômica privilegiada e que performam/performaram uma sexualidade heteronormativa. Já entre as outras quatro autorias, verificamos três vozes femininas, sendo uma delas, Stella do

5. Todas as questões aqui analisadas foram coletadas do site do Instituto Nacional de Estudos e Pesquisas Educacionais Anísio Teixeira. Disponível em https://www.gov.br/inep/pt-br/areas-de-atuacao/avaliacao-e-exames-educacionais/enem/provas-e-gabaritos. Acesso em: 11 maio 2021 
Patrocínio, negra e de classe econômica desfavorecida. Cuti, por sua vez, é trazido como uma voz masculina negra; a única em todo o exame.

Tais informações nos interessam aqui por pensarmos as literaturas de reexistência como espaços estéticos em que se rompem as fronteiras estruturalistas entre autoria e ponto de vista. Cerrando fileiras com Evaristo (2009), pensamos o conceito de "escrevivência" como um dos elementos que compõem as produções literárias de reexistência. Com efeito, categorias como raça, gênero e sexualidade são determinantes para a construção estética, já que a elaboração formal do texto literário, conforme nossa visão, também é atravessada, apesar de não engessadamente determinada, por nossas experiências como sujeitos sociais.

Traçado esse panorama inicial sobre a configuração das vozes que estruturam a arena do campo literário materializado na prova de 2018, cabe-nos agora compreender como são tratadas as questões cujos textos-base são assinados por Cuti, Stella do Patrocínio, Natália Borges Polessa e Angélica Freitas. São essas autorias que definimos como assentadas em letramentos literários de reexistência, já que performam diretamente em seus textos a opressão de raça, gênero e sexualidade, valendo-se do estético como lugar de resistência ao preconceito e de reelaboração da violência. A questão de Cuti, de número 10, é a primeira que aparece no exame:

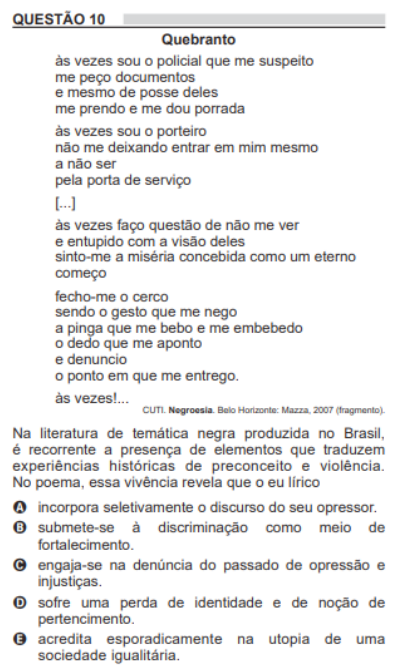

Figura 1. Questão 10

Fonte: Enem (2018)

Cuti é pseudônimo de Luiz Silva, um dos mais destacados intelectuais negros contemporâneos. Poeta, ficcionista, ensaísta e dramaturgo, Cuti formou-se em Letras pela Universidade de São Paulo (USP) e é Mestre e Doutor em Literatura pela Universidade Estadual de Campinas (Unicamp). Militante fortemente engajado na luta contra o racismo, Cuti foi um dos fundadores da ONG Quilombhoje Literatura, responsável pela série Cadernos Negros, periódico destinado à publicação de poemas e contos de autorias negras desde 1978.

No que se refere à questão em foco, observa-se que seu texto-base, "Quebranto", pertence ao gênero poema, tendo sido publicado no livro Negroesia - neologismo que reafirma uma poesia de autoria negra. Tal reafirmação se reforça pelo próprio lugar de publicação do poema, a Editora Mazza, cuja compromisso é fazer circular obras referentes à cultura afro-brasileira. "Quebranto" - uma espécie de feitiço maléfico - nos dá a conhecer um sujeito poético que põe em xeque a introjeção do próprio opressor - o "policial", o "porteiro", o "eles" - em seus movimentos, como uma forma, talvez, de maldição, de "quebranto". A voz desse sujeito, que se cola à experiência de Cuti como homem negro, vale-se do terreno estético como espaço de reinvenção desse racismo que, de tão estrutural, invade o próprio sujeito negro, "às vezes...". Observa-se, portanto, na configuração dessa prática de letramentos literários que é o poema em análise, uma disputa, em movimento heterodiscursivo, entre forças centrípetas - aquelas que, pedindo o documento, colocando o dedo em riste e apontando a porta de serviço, acenam para um discurso hegemônico, racista - e forças centrífugas, aquelas que fazem o sujeito dizer, refletir e reelaborar, no estético, a opressão que, não raro, se manifesta em suas próprias ações.

O enunciado da questão, como se pode observar, parte do lugar da experiência da literatura de autoria negra como um lugar marcado pela tematização da opressão e da violência, para aferir se o candidato consegue compreender 
de que modo se configura, esteticamente, a vivência do sujeito que diz. Verifica-se, assim, que há, na configuração da questão, certo afinamento com o que defendemos aqui como letramentos literários de reexistência, visto que, embora não explícita, há, no enunciado, a compreensão de que conhecer previamente a experiência da autoria é uma estratégia de leitura importante para que se possam produzir significados acerca do modo como a vivência do racismo se configura do ponto de vista estético. A alternativa correta - letra A - reforça nosso entendimento, uma vez que requer do estudante que perceba o discurso (literário) como uma trama em que se dialogizam diferentes vozes e na qual o sujeito performa, tornando-se responsivo frente a dizeres outros.

Dez questões após, observamos pergunta referente a trecho do conto "Vó, a senhora é lésbica?", do livro Amora (2015), de Natália Borges Polesso:

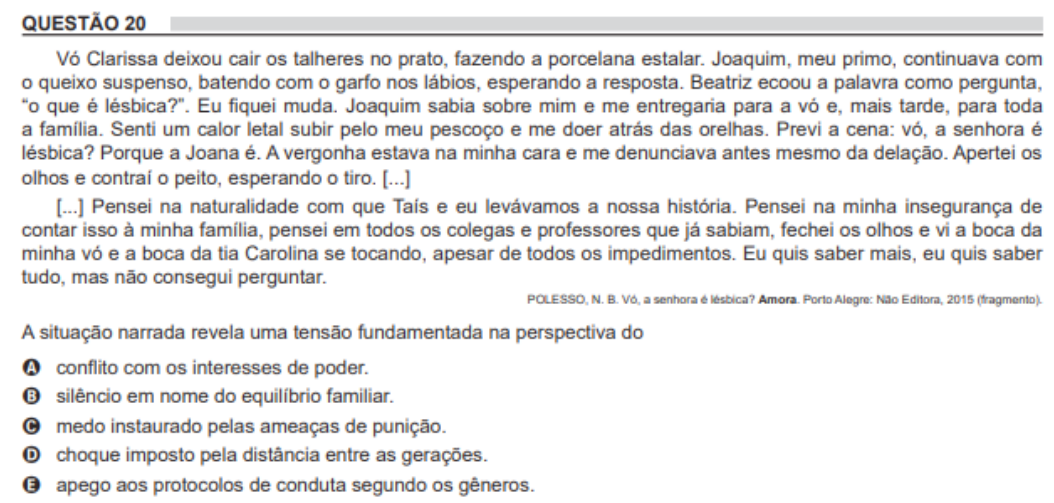

Figura 2. Questão 20

Fonte: Enem (2018)

Amora, livro de contos, foi publicado em 2015, pela Não Editora, um selo da Editora Dublinense. Tal selo, como consta no site da própria editora, é dedicado à publicação de uma literatura brasileira que fuja aos padrões editoriais do mercado, oferecendo aos leitores aqueles livros que eles querem ler, mas ainda não sabem ${ }^{6}$. Natália Borges Polesso é uma mulher branca, pesquisadora, escritora e tradutora. Hoje, compõe o catálogo de autoras da Companhia das Letras, umas das principais editoras do país. Amora recebeu, em 2016, o Prêmio Jabuti.

O conto "Vó, a senhora é lésbica?" trata de uma situação tensa vivida pela narradora-personagem ao imaginar que teria sua orientação sexual revelada à família por meio de uma pergunta que o primo faz à avó, a qual mantém um relacionamento homoafetivo quase tácito com Carolina. Na íntegra do conto, a narradora ouve da avó a resposta assertiva à pergunta do neto, além de tomar conhecimento de como a relação entre as duas senhoras teria se desenrolado. Ainda assim, a personagem não tem coragem de falar sobre sua namorada, Taís, e de perguntar mais sobre a história da avó: "Eu quis saber mais, eu quis saber tudo, mas eu não consegui."

Focando apenas no trecho destacado na questão, observa-se, de fato, uma construção narrativa fundada na tensão, como aponta o enunciado: diante da possível voz centrípeta da família, a narradora sente medo de ter sua voz, centrífuga à heteronormatividade, despida. Esse movimento se materializa esteticamente no conto de diversos modos, dentre eles pelas imagens construídas: "calor letal", "doer", "tiro". A tensão experimentada pela personagem se dá frente à possibilidade da "delação", uma revelação da ordem da denúncia. Portanto, as imagens destacadas operam como forças, vozes que emudecem o direito e/ou o conforto de a narradora ser. A história da avó aparece, assim, como um espaço de alento frente à opressão. $\mathrm{O}$ ato de narrar e ouvir configuram-se, desse modo, como um ato possível de reexistir.

Todo esse movimento estético, porém, perde-se na construção do enunciado da questão. Do estudante parece apenas se demandar o reconhecimento da causa da tensão vivida pela personagem, esperando-se, portanto, uma leitura mais referencial do trecho fundada numa abordagem autônoma dos letramentos. A construção estética que marca o discurso literário ali posto na dimensão da "escrevivência" e da reexistência fica esmaecida. Nada disso, porém, anula a importância de o texto por si mesmo constar no repertório de um exame nacional como o Enem. Ali estar já configura uma ação importante, quando pensamos nos embates que estruturam o campo literário, especialmente num contexto ideológico tão conservador como o atual, no Brasil. Tanto é assim que a questão provocou polêmica entre

6. Cf.: https://dublinense.com.br/nao-editora/. Acesso em 20 jun. 2021. 
grupos de extrema-direita, que acusaram a prova de fazer "sindicalismo sexual"7 - expressão essa incomum e cujo sentido só pode ser inferido no contexto no qual foi criado.

A questão 30, por sua vez, traz o poema de Stela do Patrocínio, que, como já apontamos, é a voz considerada por nós mais à parte do campo literário brasileiro estabelecido. A obra Reino dos bichos e dos animais é meu nome, organizada por Viviane Mosé a partir da transcrição de falas/poemas gravadas/os em fitas cassetes, foi publicada postumamente por uma editora de pequeno porte, apesar de bastante prestigiada entre a crítica literária, a Azougue.

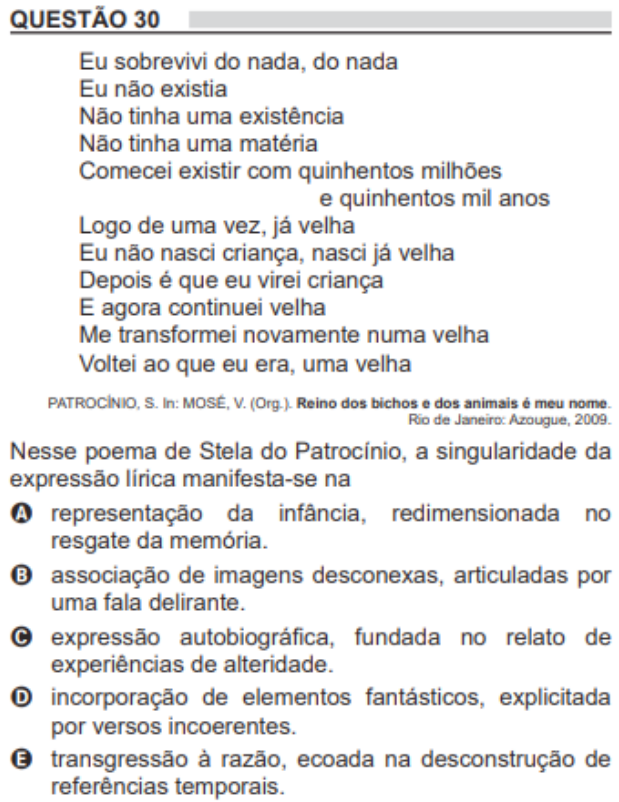

Figura 3. Questão 30

Fonte: Enem (2018)

No trecho do poema trazido pelo exame, Patrocínio parece falar de um eu em constante transformação, em movimento, ao enxergar a circularidade da experiência identitária. Obra construída fora de qualquer escola ou movimento literário, há na poética de Patrocínio um falar de/por si mesmo por meio da construção de reflexões sobre o paradoxo de sua própria existência. A existência de Stela do Patrocínio, inclusive, parece ter sido reconhecida apenas - como podemos compreender a partir da própria leitura do poema na íntegra - quando, já adulta, a autora dá voz a sua história gravando fitas com o que chama de seu "falatório" enquanto se encontrava internada numa instituição especializada no tratamento de pacientes com questões mentais.

Apesar, no entanto, da potencialidade da obra de Patrocínio para se pensar esteticamente na existência da mulher, negra e com problemas mentais, a partir da leitura literária, a questão, ao apontar a alternativa E como a correta, parece se preocupar mais com a compreensão sobre a distorção da construção lógica dos significados do texto ao considerar que a "singularidade da expressão lírica" do excerto seria manifestado pelo uso das dissonantes referências temporais como em "nasci já velha / depois é que eu virei criança". Dessa forma, mais uma vez, o Enem, embora traga um texto de relevância para se pensar outras formas de ser/existir, o que, por si só, já é positivo, deixa de dialogar com visões mais ideológicas dos letramentos ao não abordar o texto de Stela do Patrocínio como uma poética de reexistência.

Cinco questões depois, na atividade de número 35, o Enem traz um poema de Um útero é do tamanbo de um punbo, segundo livro de poesias de Angélica Freitas, que dialoga diretamente com a questão feminista já a partir de seu título. Parece ser intuito da autora em seus poemas a denúncia/desconstrução de preconceitos e discursos sobre a mulher ainda em voga em nossa sociedade.

7. Cf.: https://paginacinco.blogosfera.uol.com.br/2018/11/06/vo-a-senhora-e-lesbica-leia-o-conto-que-causou-polemica-no-enem/. Acesso em 09 de Jun. 2021. 


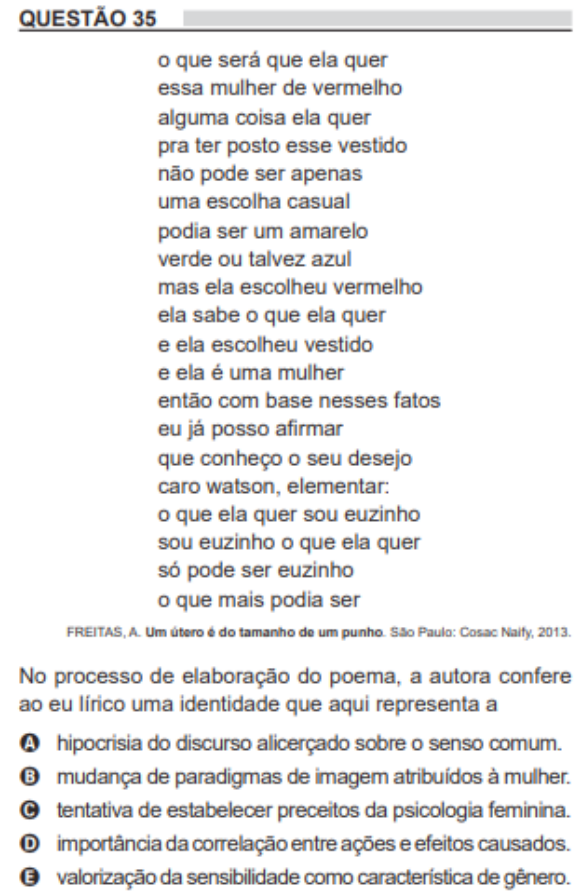

Figura 4. Questão 35

Fonte: Enem (2018)

O poema em destaque na questão se constrói por versos livres, numa linguagem coloquial, sob um enquadre irônico e se constitui heterodiscursivamente ao trazer à baila discursos sobre a mulher normalmente fundados numa base misógina da sociedade e que se materializam no gênero a partir da ideia de que uma mulher se arruma - no caso, ao usar um vestido vermelho -, porque deseja um homem. Esse discurso, que no poema se constrói a partir da voz do possível abusador/estuprador, se alinha àqueles que culpabilizam as próprias mulheres pelos abusos sofridos, normalizando instintos e atitudes sexuais supostamente naturais ao homem. O masculino é, então, enxergado egocentricamente como o centro da estrutura social e a mulher, por sua vez, agiria na órbita dessa figura: "o que ela quer sou euzinho / (...) o que mais poderia ser".

A questão proposta parece alinhar-se a visões ideológicas e de reexistência dos letramentos literários, ao solicitar que o candidato compreenda criticamente a identidade atribuída pela autora ao eu lírico do poema. O gabarito da prova sugere a alternativa A - bipocrisia do discurso alicerçado sobre o senso comum - como a correta, o que mais uma vez reforça o caráter crítico da questão ao considerar os discursos machistas que atravessam nossa sociedade como "senso comum" e o poema, de certo modo, como uma produção literária que denuncia a "hipocrisia" desse senso comum. Dessa forma, o Enem parece possibilitar a compreensão da literatura como espaço de reexistência e luta contra discursos opressores que circulam em nossa sociedade ao mesmo tempo em que averigua a compreensão do candidato sobre conceitos e recursos do tecido literário.

A prova de 2019 do Enem traz, dentre as 45 questões da seção de Linguagens, Códigos e suas Tecnologias, novamente, apenas 15 destinadas à abordagem direta dos saberes literários em português. Dentre essas 15 questões, 11 trazem textos de nomes já consagrados no campo literário, tais como Arthur Conan Doyle, Oswald de Andrade, Érico Veríssimo, Ivan Ângelo, João Cabral de Melo Neto, Raul Pompéia, Hilda Hilst, Marinetti, Moacyr Scliar, Mauro Mota e Heitor Villa-Lobos. Outras 2 trazem textos de autores que, apesar de contemporâneos, têm suas produções literárias já reconhecidas pela academia, sendo esses autores, inclusive, frutos dessa mesma academia, como é o caso de Vitor Henringer, graduado em Letras pela Universidade Federal do Rio de Janeiro e vencedor do prêmio Jabuti em 2013, e Ana Maria Marques, Mestra em Literaturas pela Universidade Federal de Minas Gerais e vencedora do Prêmio Alphonsus de Guimaraens em 2012. As questões restantes abordam músicas de Cazuza e de Naiara Azevedo. Cazuza, cantor brasileiro abertamente LGBTQIA+, é trazido a partir de um trecho da canção Blues da Piedade, que, além de não se enquadrar numa das facetas identitárias em foco neste artigo - gênero, raça e sexualidade -, é tomada como pretexto para a averiguação da habilidade de reconhecimento de tipologias textuais. Mais interessante, no 
entanto, é a canção de Naiara Azevedo, cantora paraense, mulher-cis e branca, composta, como afirma o próprio enunciado da questão, "para uma campanha de combate à violência contra mulheres".

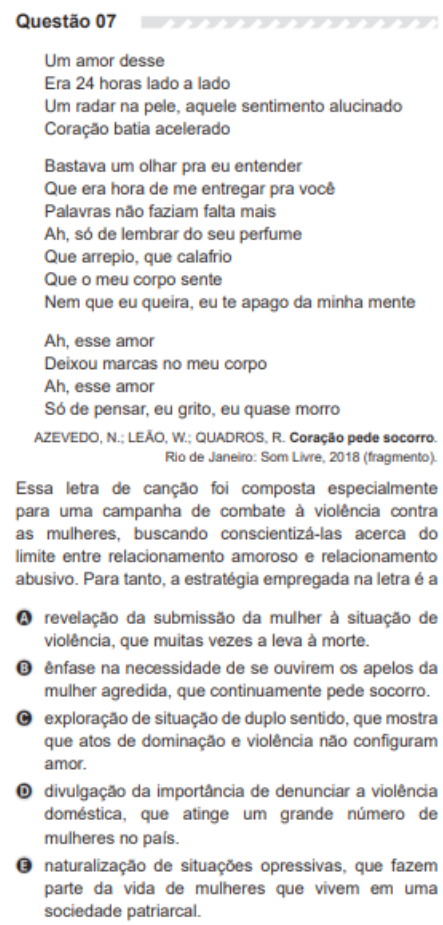

Figura 5. Questão 07

Fonte: Enem (2019)

Mesmo considerando que a canção foi composta com parceiros, temos um texto escrito por uma mulher que dialogiza discursos sobre relacionamentos abusivos. Para tanto, o texto é composto heterodiscursivamente por vozes que, ao mesmo tempo em que refratam uma percepção romântica do relacionamento possessivo ("Um amor desses / Era 24 horas lado a lado" e "Bastava um olhar pra eu entender / Que hora de me entregar pra você"), trazem discursivamente marcas e efeitos das agressões psicológicas e físicas sofridas por mulheres nessa situação ("Ah, esse amor / Deixou marcas no meu corpo / [...] Só de pensar, eu grito, eu quase morro"). Assim, a canção parece provocar a compreensão de que o mesmo vocabulário normalmente relacionado ao amor pode ser invocado na construção do discurso da violência contra a mulher.

O enunciado da questão parece se aproximar, desse modo, de perspectivas mais ideológicas, de reexistência, dos letramentos literários a partir da compreensão, a partir da análise dos recursos empregados na letra da canção, da ambiguidade provocada entre o discurso amoroso e o discurso abusivo. A alternativa indicada pelo gabarito do Enem como a correta - letra C - corrobora essa impressão, colocando o foco da questão na estratégia literária utilizada para construção de sentidos sobre «atos de dominação e violência [que] não se configuram amor».

Na edição de 2020 do Enem, temos, novamente, 15 questões, dentre as 45 da prova de Linguagens, Códigos e suas Tecnologias que abordam mais diretamente o texto literário em português. Dentre essas 15 questões, 13 apresentam autores estabelecidos pelo campo literário/musical brasileiros: Manuel Bandeira, Graça Aranha, Tom Jobim, Domingos Pellegrini, Laís Corrêa de Araújo, Dyonélio Machado, Lenine, Afonso Romano Sant'Anna, Caetano Veloso, Olavo Romano, Olavo Bilac e Dalton Trevisan. Lima Barreto, autor negro brasileiro, também é representado nesta prova, mas em questão a partir de Triste fim de Policarpo Quaresma, sem relação com a discussão racial. Além disso, temos pela primeira vez um excerto de um autor africano, Ondjaki, mas novamente em questão que não se relaciona às temáticas aqui estudadas: gênero, raça e sexualidade. Desse modo, nenhuma das questões desse exame se circunscreveram no enquadre proposto por este artigo para seleção do corpus de análise.

Nesse sentido, é perceptível uma redução gradativa das questões na esfera literária que abordam as questões de raça, gênero e sexualidade nas últimas três edições do Enem. No entanto, é importante apontar que diversas questões que não apresentavam o texto literário ou saberes literários como foco abordavam as temáticas em destaque ou até mesmo as práticas literárias de reexistência. Um exemplo é a Questão 8, que abordava o conceito de slam, 
gênero que, conforme Neves (2017), pode se configurar como uma prática literária de reexistência; entretanto, o texto gerador do enunciado reproduzido na prova é um informativo e não a própria slam poetry.

\section{CONSIDERAÇÕES FINAIS}

Propusemo-nos, neste artigo, a investigar que práticas de letramentos literários são (des)legitimadas nas questões das provas de Linguagens, Códigos e suas Tecnologias do Exame Nacional do Ensino Médio (Enem) entre 2018 e 2020, enfocando o diálogo dessas questões com textos literários que se constituem estética e discursivamente como práticas de reexistência. A escolha por essas três edições do exame, como expusemos, deu-se em razão da materialidade social, cultural, política e ideológica em que sua produção se assenta: um momento de expansão de uma agenda político-ideológica extremamente conservadora.

Ancorando-nos num instrumental teórico-metodológico que dialoga, numa perspectiva Indisciplinar da Linguística Aplicada, estudos literários sob o viés cultural, estudos dos letramentos e a Análise Dialógica do Discurso, observamos que as três edições da referida prova, no que se refere à seleção dos textos literários, apresentam, ainda, uma primazia das forças que compõem o centro do campo literário brasileiro. De modo geral, as questões baseiam-se em autorias brancas, masculinas e heterossexuais consagradas pelos fatores de constituição do cânone, talvez este o "patrimônio literário" aludido na Matriz de Referências do Enem. Há, no entanto, ainda que ocupando um espaço diminuto - e que, como afirmamos, parece vir desaparecendo ao longo dos anos de 2019 e 2020 -, a presença de textos literários mais à margem do campo literário, construídos por mulheres, pessoas negras e LGBTQIA+, que podem ser compreendidos como práticas literárias de reexistência. No entanto, na abordagem desses textos pelo Enem, é possível perceber ainda a friç̧ão entre abordagens mais tradicionais e aquelas abertamente ideológicas ou de reexistência dos letramentos literários.

Por fim, destacamos que, por fazer parte de um exame nacional, as questões que apresentam textos das chamadas literaturas de reexistência analisadas neste artigo tinham, logicamente, seus objetivos atrelados às competências/ habilidades de leitura que o Enem busca verificar, sendo construídas também a partir da consideração de níveis de dificuldade maiores ou menores. Esses fatores interferem na construção das questões, impedindo, por vezes, que abordagens mais engajadas dos letramentos literários sejam legitimadas. Nesse sentido, é imperativo ressaltar que, a partir da análise realizada, foi possível constatar como práticas de letramentos literários de reexistência podem se pasteurizar e ter seu movimento de resistir/reexistir apagado.

\section{REFERÊNCIAS}

AMORIM, M. A. \& SILVA, T. C. (2019) O ensino de literaturas na BNCC: discursos e (re)existências possíveis. In: Amorim, M. A.; Gerhardt, A. F. L. M. (orgs.). A BNCC e o ensino de línguas e literaturas. Campinas: Pontes Editores, p. 153-179.

AMORIM, M. A. de; SILVA, M. R. L. da. (2020) O ensino de literaturas na linguística aplicada brasileira. Raído, v. 14, n. 36, p. $163-189$.

AMORIM, M. A. de.; DOMINGUES, D.; NASCIMENTO, D. V. K.; SILVA, T. C. da. (No prelo). Literatura na escola. São Paulo: Contexto.

AMORIM, M. A. de; NASCIMENTO, D. V. K.; SANTOS, M. S. dos. (2021) A leitura literária no livro didático de português: uma análise dialógica. Revista Letras Raras. Campina Grande, v. 10, n. 1, p. 53-79.

BAKHTIN, M. (2011) Estética da Criação Verbal. São Paulo: Martins Fontes, 1953.

BAKHTIN, M. (2015) Teoria do Romance I: a estilística. São Paulo: Editora 34, 1975.

BAKHTIN, M. (2016) Os gêneros do discurso. São Paulo: Editora 34, 1953.

BAKHTIN, M. (2017) Para uma filosofia do ato responsável. São Carlos: Pedro e João Editores, 1920-24.

BOURDIEU, P. (1996) As regras da arte: gênese e estrutura do campo literário. Lisboa: Editorial Presença, 1992. 
BRAIT, B. (2004) Linguagem e identidade: um constante trabalho de estilo. Trabalho, Educação e Saúde, 2(1): 185-201.

BRASIL, Ministério da Educação. Matriz de Referência ENEM. Disponível em: matriz_referencia.pdf (inep.gov.br). Acesso em: 06 jun. 2021.

COSSON, R. (2006) Letramento literário: teoria e prática. São Paulo: Contexto.

PAULINO, G.; COSSON, R. (2009) Letramento literário: para viver a literatura dentro e fora da escola." In: Zilberman, R.; Rosling, T. (orgs.). Escola e leitura: velhas crises, novas alternativas. São Paulo: Global, p. 61-79.

EVARISTO, C. (2009) "Literatura negra": uma poética de nossa afro-brasilidade. SCRIPTA, Belo Horizonte, v. 13, n. 25 , p. 17-31.

FARACO, C. A. (2009) Linguagem e diálogo: as ideias linguísticas do Círculo de Bakhtin. São Paulo: Parábola.

GALLEGO, E. S. (2018) O ódio como política: a reinvenção das direitas no Brasil. São Paulo: Boitempo.

LUFT, G.; FRIZON, M. LEITE, G. LUCENA, K.; VIANNA, C. WELLER, D. (2012) A literatura no Exame Nacional do Ensino Médio (ENEM). Nonada, 18, p. 111-126.

FISCHER, L. A. (2014) O fim do cânone e nós com isso. Remate de Males, Campinas, SP, v. 34, n. 2, p. 573-611.

FREIRE, P. (2011). A importância do ato de ler. São Paulo: Cortez, 1981.

KATO, M. (1986) No mundo da escrita: uma perspectiva psicolinguística. São Paulo: Ática.

KLEIMAN, A. B. (org.). (1995) Os significados do letramento: uma nova perspectiva sobre a prática social da escrita. Campinas: Mercado de Letras.

MOITA LOPES, L. P. (org.). (2006) Por uma linguística aplicada indisciplinar. São Paulo: Parábola Editorial.

NEVES, C. A. B. (2017) Slams - letramentos literários de reexistência ao/no mundo contemporâneo. Revista Linha D’Água. São Paulo, v. 30, n. 2, p. 92-112.

PAULINO, G. (2001) Letramento literário: por vielas e alamedas. Revista da FACED, nº 05, 117-125.

REIS, C. (2013). O conbecimento da literatura: introdução aos estudos literários. $2^{\mathrm{a}}$ ed. Porto Alegre: EDIPUCRS, 1995.

SCARAMUCCI, M. (2004) Efeito retroativo da avaliação no ensino/aprendizagem de línguas: o estado da arte. Trabalhos em Linguística Aplicada, Campinas, 43 (2): 203-226.

SILVA, T. C. (2020) As viagens de um Gulever: o ensino de literatura como (re)existência na contemporaneidade. Terceira margem, v. 24, n. 44 .

SOARES, M. (2008) Leitura e democracia cultural. In: Paiva, A.; Martins, A. A.; Paulino, G.; Versiani, Z. (Orgs.). Democratizando a leitura: pesquisa e práticas. Belo Horizonte: Autêntica, p. 17-48.

SOARES, M. (1998) Letramento, um tema em três gêneros. Belo Horizonte: Autêntica.

SOARES, M. (2002) Novas práticas de leitura e escrita: letramento na cibercultura. Revista Educação e Sociedade. Campinas, vol 23, n. 81, p. $143-160$.

SOBRAL, A.; GIACOMELLI, K. (2016) Observações didáticas sobre a análise dialógica do discurso - ADD. Domínios de lingu@ gem, v. 10, n. 3 .

SOUZA, A. L. S. (2011) Letramentos de reexistência: poesia, grafite, música, dança: hip-hop. São Paulo: Parábola Editorial. 
STREET, B. (2003) What's "new" in new literacy studies?: critical approaches to literacy in theory and practice. Disponível em: <http://www.people.iup.edu/gnvp/D-K/articles/from\%20Atsushi/Street\%20\%282003\%29.pdf> Acesso em 13 jun. 2019.

STREET, B. (2014) Letramentos sociais: abordagens críticas do letramento no desenvolvimento, na etnografia e na educação. Trad. Marcos Bagno. São Paulo: Parábola.

STREET, B. (1984) Literacy in Theory and Practice. New York: Cambridge University Press.

TFOUNI, L. V. (1988) Adultos não alfabetizados: avesso do avesso. Campinas: Pontes Editores.

VOLÓCHINOV, V. (2017) Marxismo e filosofia da linguagem. Tradução, notas e glossário de Sheila Grillo e Ekaterina Vólkova Américo. São Paulo: Editora 34, 1929. 